\title{
Intrapartum ultrasound to predict vaginal labor: a prospective cohort study
}

\author{
Helene Ingeberg1, Anna Miskova ${ }^{1,2,3}$, Diana Andzane ${ }^{1,2,3 *}$
}

\begin{abstract}
${ }^{1}$ Department of Obstetrics and Gynecology, Riga Stradins University, Riga, Latvia
${ }^{2}$ Department of Clinical Skills and Medical Technologies, Riga Stradins University, Riga, Latvia

${ }^{3}$ Department of Obstetrics, Riga Maternity Hospital, Riga, Latvia
\end{abstract}

Received: 28 August 2017

Accepted: 25 September 2017

\author{
*Correspondence: \\ Dr. Diana Andzane, \\ E-mail: andzane.diana@gmail.com
}

Copyright: ( $\odot$ the author(s), publisher and licensee Medip Academy. This is an open-access article distributed under the terms of the Creative Commons Attribution Non-Commercial License, which permits unrestricted non-commercial use, distribution, and reproduction in any medium, provided the original work is properly cited.

\section{ABSTRACT}

Background: Non-invasive transperineal ultrasound has been used to detect the descent of the fetal head using headperineum distance (HPD) and angle of progression (AOP). The aim was to evaluate HPD and AOP as predictors of vaginal delivery in the first stage of labor.

Methods: This was a prospective cohort study in Riga Maternity Hospital in Latvia from May till August 2016. The study included only nulliparous women with singleton pregnancies and cephalic presentation. Ultrasound was used to measure HPD and AOP. Data was collected on demographics, labor parameters and outcome.

Results: Of 36 women enrolled, $26(72.2 \%)$ had a vaginal delivery. The area under the receiver-operating characteristics curve for the prediction of vaginal delivery was 0.865 (95\% confidence interval (CI) $0.75-0.98)$ using HPD as the test variable and the area under the curve was 0.877 (95\% CI 0.77-0.99) for AOP. The median HPD was lower in the women delivering vaginally than in the women delivering by cesarean section $(\mathrm{P}<0.001)$. HPD was $\leq 40$ $\mathrm{mm}$ in $18(50 \%)$ women, of whom all delivered vaginally. HPD was $>40 \mathrm{~mm}$ in the other 18 women, of whom 8 $(22.2 \%)$ delivered vaginally $(\mathrm{P}<0.001)$. AOP was $\geq 105^{\circ}$ in $22(61.1 \%)$ women and, of these, 21 delivered vaginally. AOP was $<105^{\circ}$ in the other $14(38.9 \%)$ women, of whom 5 delivered vaginally $(\mathrm{P}<0.001)$.

Conclusions: $\mathrm{HPD} \leq 40 \mathrm{~mm}$ and $\mathrm{AOP} \geq 105^{\circ}$ are both predictive of vaginal delivery in the first stage of labor.

Keywords: Angle of progression, Head perineum distance, Intrapartum ultrasound, Transperineal ultrasound

\section{INTRODUCTION}

Women in active labor are clinically assessed to determine cervical dilation and fetal station by regular digital vaginal examinations (digital VE). ${ }^{1}$ Digital VE's have been deemed unreliable and subjective. ${ }^{2}$ Akmal et al. reported that digital $\mathrm{VE}$ failed to determine the fetal head position in $34 \%$ of laboring women, and incorrectly determined head position in $51 \%$ of patients in whom the position could be defined. . $^{3,4}$

Digital VE are shown to be associated with infection ascending to the fetus, chorioamnionitis, endometritis and shortened time interval to delivery in preterm labor. ${ }^{5,6}$ Digital VE have also been shown to frequently be experienced as painful and embarrassing to the women being examined. ${ }^{7}$

Non-invasive transperineal ultrasound has been used to detect the descent of the fetal head using head-perineum distance (HPD), described as shortest distance from the fetal head to the perineum, and angle of progression (AOP) described as the angle between a line through the midline of the pubic symphysis and a line from the inferior apex of the symphysis to the leading part of the fetal skull. 
An angle of progression of $120^{\circ}$ or greater is an excellent predictor of a successful vaginal delivery. ${ }^{4}$ These parameters are objective evaluations of fetal head station and are shown to have low intra- and interoperator variability. $^{8-11}$

The aim of this study was to assess the value of HPD and AOP in predicting the mode of delivery when measured in the first stage of labor.

\section{METHODS}

This was a prospective cohort study in Riga Maternity Hospital in Latvia from May till August 2016. The study was approved by the Stradins Council of Ethics, and included only nulliparous women with singleton pregnancies, cephalic presentation and normal Body mass index (BMI). Written informed consent was obtained from all participants prior to enrolment.

Onset of first stage of labor was diagnosed as regular contractions and cervical dilation 3-4 cm. The measurements were obtained by doctors at the Riga Maternity Hospital making a brief visit to the patient only to obtain the ultrasound measurement data, which was later re-affirmed with Image-J. Transperineal ultrasound was used to measure HPD and AOP. The HPD cutoff value for prediction of vaginal delivery was chosen in accordance with other studies, and the AOP cutoff value was calculated from the predictive value found in this study. ${ }^{12}$ The examination was conducted with a Philips VISIQ ultrasound system. The ultrasound transducer was covered with gel and a sterile glove, and pressed firmly to the labia majora when obtaining the measurements. To measure HPD the transducer was held in a transverse plane on the vulva at the level of the posterior commissure and pressed against the pubic rami, and the distance from the fetal head to the perineum was measured and recorded. AOP was measured in the sagittal plane, by drawing a line through the long axis of the symphysis and another line tangential to the fetal head and measuring the angle in between the two lines.

\section{Statistical analysis}

The predictive values of the ultrasound measurements were derived with cross-table analysis and receiveroperating characteristic curves computing the area under the curve (AUC) as a discriminator. The AUC was considered to have discriminatory potential if the lower limit of the 95\% CI interval exceeded 0.5 . Fisher's exact and Mann-Whitney U tests were used to test parameters, and $\mathrm{P}<0.001$ was considered statistically significant. Data was analyzed with the statistics package SPSS v.23.

\section{RESULTS}

Clinical characteristics of the study population are shown in Table 1. Of 36 women enrolled, 26 (72.2\%) had a vaginal delivery ( 22 women spontaneously and 4 women with vacuum). 10 women had a cesarean section, 2 due to fetal distress, 7 due to failure to progress and 1 due to cephalopelvic disproportion.

Table 1: Demographics and clinical characteristics of 36 nulliparous women in the first stage of labor.

\begin{tabular}{|ll|}
\hline Characteristic & Median (range) or $\mathbf{n}(\%)$ \\
\hline Maternal & \\
\hline Maternal age (years) & $27.5(20-40)$ \\
\hline Body mass index $\left(\mathrm{kg} / \mathrm{m}^{2}\right)$ & $23(19-29)$ \\
\hline Labor & $25(69)$ \\
\hline Oxytocin augmentation & $10(28)$ \\
\hline Cesarean section delivery & 2 \\
\hline Due to fetal distress & 1 \\
\hline Cephalopelvic disproportion & 7 \\
\hline Prolonged first stage & 3 \\
\hline Operative vaginal delivery vacuum & \\
\hline Neonatal & $3835(2460-5100)$ \\
\hline Birthweight (grams) & $8(6-9)$ \\
\hline Apgar score & $9(8-10)$ \\
\hline At 1 minute & \\
\hline At 5 minutes & \\
\hline
\end{tabular}

The area under the receiver-operating characteristics (ROC) curve for the prediction of vaginal delivery was 0.865 (95\% confidence interval (CI) 0.75-0.98; P <0.001) using HPD as the test variable (Figure 1) and the area under the curve was 0.877 (95\% CI 0.77-0.99; P <0.001) for AOP (Figure 2).

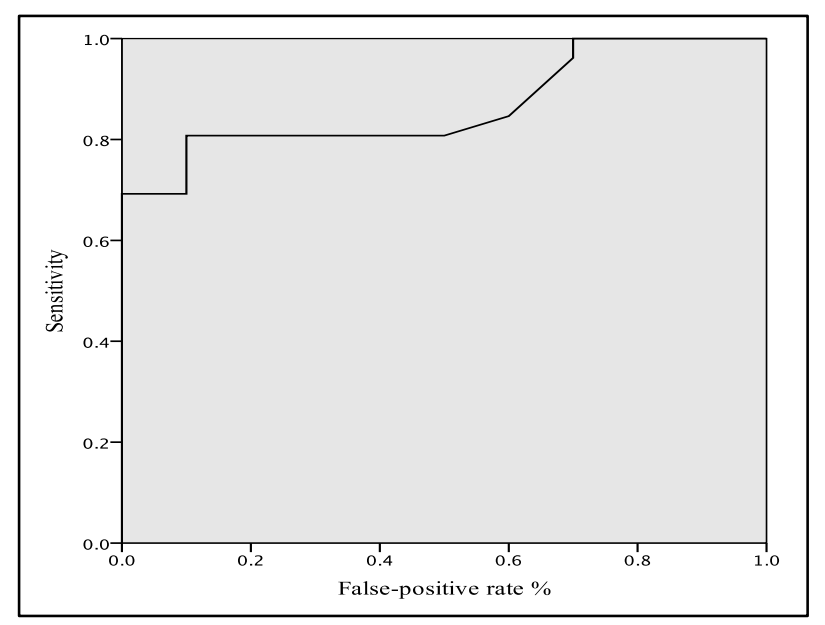

Figure 1: Receiver-operating characteristics curve for head-perineum distance in nulliparous women in the

first stage of labor in the prediction of vaginal delivery (area under the curve $=0.865, P<0.001$ ).

The median HPD was lower in the women delivering vaginally than in the women delivering by cesarean section (Mann-Whitney $\mathrm{U}=35.0 ; \mathrm{P}<0.001$ ) (Figure 3). HPD was $\leq 40 \mathrm{~mm}$ in $18(50 \%)$ women, of who all delivered vaginally. HPD was $>40 \mathrm{~mm}$ in the other 18 (50\%) women, of whom 8 (22.2\%) delivered vaginally, a difference of $77.8 \%$ (95\% CI 66.56-86.14; $\mathrm{P}<0.001$ ). AOP was $\geq 105^{\circ}$ in $22(61.1 \%)$ of the women, of which $21(58.33 \%)$ delivered vaginally. AOP was $<105^{\circ}$ in the other $14(38.9 \%)$ women, of whom $5(19.2 \%)$ delivered 
vaginally. A difference of $76.25 \%$ (95\% CI 41.79-92.41; $\mathrm{P}<0.001)$.

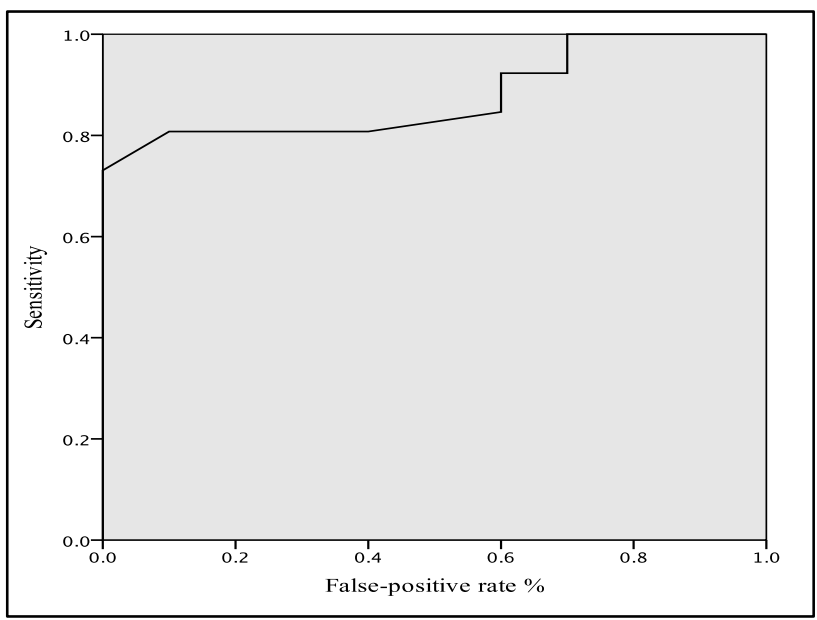

Figure 2: Receiver-operating characteristics curve for angle of progression in nulliparous women in the first stage of labor in the prediction of vaginal delivery (area under the curve $=\mathbf{0 . 8 7 7}, \mathrm{P}<\mathbf{0 . 0 0 1}$ ).

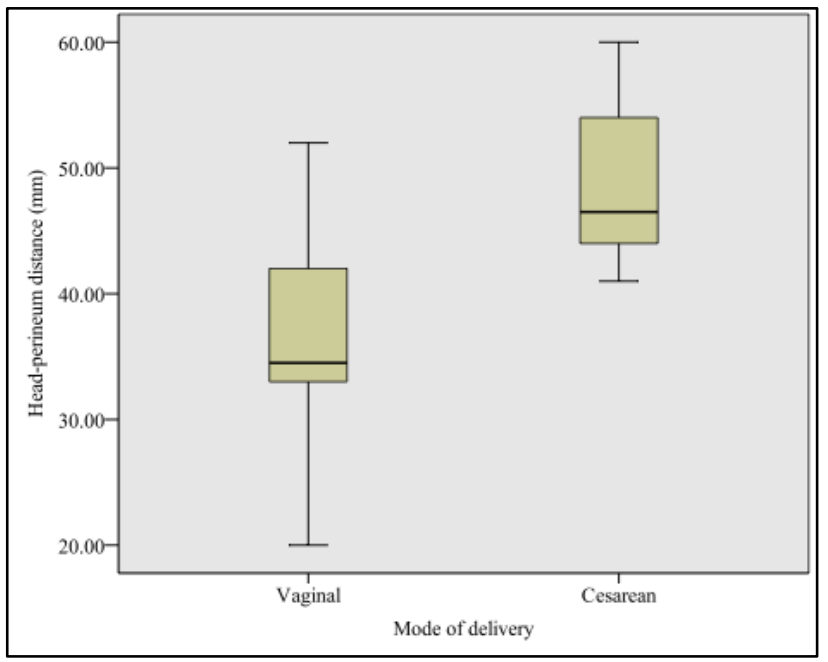

Figure 3: Head-perineum distance in nulliparous women in the first stage of labor, comparing those who went on to deliver by Cesarean section $(n=10)$ with those who delivered vaginally $(n=26)($ MannWhitney $U=35.0 ; P<0.001)$.

\section{DISCUSSION}

We found that transperineal ultrasound measurements of HPD and AOP in the first stage of labor contributes clinically significant information about the chance for vaginal labor outcome in nulliparous women. All of the women who had HPD $<40 \mathrm{~mm}$ had a vaginal delivery, and other studies have emphasized that using a cutoff value of $40 \mathrm{~mm}$ for HPD is predictive of vaginal delivery, which is further substantiated by this study. ${ }^{10}$ The reproducibility of AOP has been illustrated as well as the low intra- and inter observer variation for HPD. ${ }^{10,13,14}$
In others studies an AOP of $120^{\circ}$ and $110^{\circ}$ have been used as a cutoff. ${ }^{8,12}$ In present study we found that the cutoff value of $105^{\circ}$ was predictive of vaginal delivery, and this range of $15^{\circ}$ difference may be due to interobserver variation.

An argument can be made for HPD being more synchronously reproduced from study to study than AOP, and due to the lower variability HPD may be considered a more reliable indicator.

Further studies are needed on the predictive and implementable value of transperineal ultrasound when it is influencing clinical decision-making. Present study indicates that intrapartum ultrasound may assist doctors and midwives in predicting labor outcome. If intrapartum ultrasound measurements made in the first stage of labor is successfully implemented into clinical practice, this patient group may benefit from a reduced number of medical interventions and the prompt initiation of medical interventions when they are required, with the prospect of reducing maternal and fetal morbidity and mortality.

\section{ACKNOWLEDGMENTS}

Authors would like to thank the mothers who participated in this study, and express our gratitude to Ieva Strele at the RSU Statistics Unit of the Faculty of Medicine.

Funding: No funding sources Conflict of interest: None declared

Ethical approval: The study was approved by the Institutional Ethics Committee

\section{REFERENCES}

1. Cunningham F, Leveno KJ, Bloom SL, Hauth JC, Rouse DJ, Spong CY. Normal labor and delivery. In: Cunningham F, Leveno KJ, Bloom SL, Hauth JC, Rouse DJ, Spong CY, eds. Williams obstetrics. 23rd ed. New York, NY: McGraw-Hill;2010:374-410.

2. Dupuis O, Silveira R, Zentner A, Dittmar A, Gaucherand P, Cucherat M, et al. Birth simulator: reliability of transvaginal assessment of fetal head station as defined by the American College of Obstetricians and Gynecologists classification. Am J Obstet Gynecol. 2005;192:868-874.

3. Akmal S, Tsoi E, Kametas N, Howard R, Nicolaides $\mathrm{KH}$ : Intrapartum sonography to determine fetal head position. J Matern Fetal Neonatal Med. 2002;12:1727.

4. Molina FS, Nicolaides KH. Ultrasound in labor and delivery. Fetal Diagn Ther. 2010;27:61-67.

5. Seaward PG, Hannah ME, Myhr TL, Farine D, Ohlsson A, Wang EE, et al. International Multicentre term prelabor rupture of membranes study: Evaluation of predictors of clinical chorioamnionitis and postpartum fever in patients with prelabor 
rupture of membranes at term. Am J Obstet Gynecol. 1997;177(5):1024-29.

6. Westover T, Knuppel RA. Modern management of clinical chorioamnionitis. Infect Dis Obstet Gynecol. 1995;3(3):123-32.

7. Ying Lai C, Levy V. Hong Kong Chinese women's experiences of vaginal examinations in labour. Midwifery. 2002;18(4):296-303.

8. Barbera AF, Pombar X, Perugino G, Lezotte DC, Hobbins JC. A new method to assess fetal head descent in labor with transperineal ultrasound. Ultrasound Obstet Gynecol. 2009;33:313-9.

9. Henrich W, Dudenhausen J, Fuchs I, Kamena A, Tutschek B. Intrapartum translabial ultrasound (ITU): sonographic landmarks and correlation with successful vacuum extraction. Ultrasound Obstet Gynecol. 2006;28:753-60.

10. Eggebø TM, Gjessing LK, Heien C, Smedvig E, Økland I, Romundstad P, et al. Prediction of labor and delivery by transperineal ultrasound in pregnancies with prelabor rupture of membranes at term. Ultrasound Obstet Gynecol. 2006;27:387-91.
11. Tutschek B, Braun T, Chantraine F, Henrich W. A study of progress of labour using intrapartum translabial ultrasound, assessing head station, direction, and angle of descent. BJOG. 2011;118:629.

12. Eggebø TM, Hassan WA, Salvesen KÅ, Lindtjørn E, Lees CC. Sonographic prediction of vaginal delivery in prolonged labor: a two-center study. Ultrasound Obstet Gynecol. 2014;43(2):195-201.

13. Ghi T, Contro E, Farina A, Nobile M, Pilu G. Threedimensional ultrasound in monitoring the progression of labor: a reproducibility study. Ultrasound Obstet Gynecol. 2010;36:500-6.

14. Molina FS, Terra R, Carrillo MP, Puertas A, Nicolaides KH. What is the most reliable ultrasound parameter to assess fetal head descent? Ultrasound Obstet Gynecol. 2010;36(4):493-9.

Cite this article as: Ingeberg $\mathrm{H}$, Miskova $\mathrm{A}$, Andzane D. Intrapartum ultrasound to predict vaginal labor: a prospective cohort study. Int J Reprod Contracept Obstet Gynecol 2017;6:4778-81. 